\title{
Transgressão da lei como uma busca de limites
}

\author{
Transgression of the law as a search for limits
}

Gabriela Weber Itaquy ${ }^{[a]}$, Cristiane Silva Esteves ${ }^{[b]}$

\section{Resumo}

[a] Psicóloga graduada pelo Centro Universitário Franciscano (Unifra), pós-graduanda em Atendimento Clínico, ênfase em Psicanálise pela Universidade Federal do Rio Grande do Sul (UFRGS), Porto Alegre, RS Brasil, e-mail:

gabi.itaquy@hotmail.com

${ }^{[b]}$ Psicóloga pela Pontifícia Universidade Católica do Rio Grande do Sul (PUCRS), mestranda em Psicologia Clínica pela mesma universidade, no Grupo de Pesquisa Avaliação e Intervenção no Ciclo Vital, pós-graduanda em Atendimento Clínico, ênfase em Psicanálise, pela Universidade Federal do Rio Grande do Sul (UFRGS), Porto Alegre, RS - Brasil, e-mail: crissilvaesteves@gmail.com

Recebido: $01 / 08 / 2011$ Received: 08/01/2011

Aprovado: 06/12/2011 Approved: $12 / 06 / 2011$
A transgressão das leis pelo meio da violência tem sido alvo de estudos e preocupações devido à grande proporção que vem tomando dentro da sociedade. Atos de violência contra as pessoas tornam-se cada vez mais frequentes na sociedade contemporânea. Diante da imprevisibilidade das ações violentas, é crescente o sentimento de impotência diante delas por parte da população. Isso acaba gerando, no imaginário individual e coletivo, a representação da violência como sendo uma força incontrolável. Vários fatores nos possibilitam supor o que impulsiona esses atos infracionais, entre estes estão a desagregação familiar e o ambiente cultural. A função do pai é de apresentar a Lei para o filho, o que vai direcioná-lo para outros interesses na cultura. Sendo assim, com o presente artigo, pretende-se obter uma melhor compreensão, por meio da Psicanálise, acerca da violência, suas expressões e repercussões nos relacionamentos sociais. 0 presente estudo, de natureza teórica, parte de uma pesquisa bibliográfica. A partir da revisão bibliográfica realizada e com o aumento dos atos de violência na sociedade moderna, percebe-se um fracasso da lei, da autoridade simbólica da função paterna. A violência tem sido percebida como uma desestabilização do equilíbrio social da civilização, sendo permeada devido à falta de leis. Com isso, entende-se que a transgressão da Lei pode ser uma busca de limites, uma procura por um Pai castrador que possa interditar/barrar esses instintos.

Palavras-chave: Lei. Transgressão. Limites. Violência. Psicanálise.

\begin{abstract}
The transgression of the laws by means of violence has been investigated and concerns due to the large proportion that has been taking place in society. Acts of violence against people become increasingly frequent in contemporary society. Given the unpredictability of violent acts, there is a growing feeling of helplessness in the face to them by the population. This ends up generating the individual and collective imagination, too, the portrayal of violence as an unstoppable force. Several factors enable us to guess what drives these infractions, among these are family breakdown and cultural environment. The father's role is to present the Law to the child, which will direct you to other interests in culture. So with this article, we intend to gain a better understanding, through psychoanalysis, about violence, its expressions and effects in
\end{abstract}


social relationships. This study is a theoretical nature, from a literature search. From the literature review and the rise of violence in modern society, we find a failure of the law and of the symbolic authority of the paternal function. The violence has been perceived as a destabilization of the social balance of civilization, being permeated due to lack of laws. This means that the transgression of the law can be a search for limits, a search for a castrating father who can ban / stop these instincts.

Keywords: Law. Transgression. Limits. Violence and psychoanalysis.

\section{Introdução}

Na sociedade atual, a violência acabou se tornando tão constante e previsível no nosso cotidiano que estamos deixando de vê-la como um evento extraordinário. Estamos sendo influenciados pela sua presença difusa, que, progressivamente, nos leva a incorporá-la como um elemento inerente à contemporaneidade. Entretanto, ao adotarmos essa perspectiva, como efeito, acabamos reduzindo nossas expectativas em relação à possibilidade de enfrentar e compreender as verdadeiras causas de sua expansão na vida social (Andrade \& Bezerra, 2009).

A transgressão das leis pelo meio da violência tem sido alvo de estudos e preocupações devido à grande proporção que vem tomando dentro da sociedade. Atos de violência contra as pessoas tornam-se cada vez mais frequentes, no trabalho, na escola, no trânsito, contra os próprios familiares. Assim, uma enorme quantidade de casos violentos ocorre diariamente, sobrepondo-se o risco de tornarem-se banais; porém, quando se divulgam algumas situações de extrema agressividade, uma revolta intensa abala a população, que fica se perguntando o que estaria acontecendo na sociedade para tais crimes ocorrerem.

De acordo com Costa (2003), a violência vem tomando conta de todas as maneiras de relação do sujeito na sua vida. Vários fatores nos possibilitam supor o que impulsiona esses atos infracionais, entre estes estão a desagregação familiar e o ambiente cultural. Esse conjunto de situações acaba contribuindo para que determinados adolescentes sejam expostos constantemente aos perigos da sociedade que os incorpora no mundo do crime. Para Martins, Catozzi e Sayegh (2005), a maioria dos adolescentes que cometem ato contrário à lei provém de famílias carentes e um tanto desorganizadas. 0 pai é, em geral, uma figura ausente, principalmente devido a fatores relacionados ao alcoolismo, abandono, prisão e uso de drogas. Já a mãe é uma figura mais presente; no entanto, também ocorrem casos de ausência decorrentes de abandono, falecimento, prostituição, psicose e prisão.

Diante dessa estrutura familiar, o adolescente acaba por vivenciar agressões e pressões para trabalhar e ajudar a família, o que o leva a buscar na rua o que lhe faltou, na busca por algo para completar seu sentimento de vazio, ou seja, uma complementação das carências sofridas dentro de casa. É nesse momento que o adolescente convive e incorpora valores ilegitimados socialmente, incluindo em sua vida o início de pequenos crimes como uma forma de pedir ajuda ao outro.

Assim, nesse artigo, pretende-se obter uma melhor compreensão acerca da violência, suas expressões e repercussões nos relacionamentos sociais, buscando-se estudar o referido tema pelo viés da psicanálise, observando-o como uma possível necessidade existente de transgressão da lei.

0 presente estudo, de natureza teórica, parte de uma pesquisa bibliográfica. Para Martins e Bicudo (1989), a pesquisa bibliográfica é desenvolvida a partir de material que já foi elaborado, constituída principalmente de artigos científicos.

\section{A violência e suas repercussões sociais}

A violência é considerada um dos eternos problemas da humanidade. Até hoje, não há sociedade em que a violência não tenha estado presente. Pelo contrário, a dialética do desenvolvimento social traz à tona os problemas mais vitais e angustiantes do ser humano (Costa, 2003).

Segundo o Dicionário Houaiss, violência é a "ação ou efeito de violentar, de empregar força física (contra alguém ou algo) ou intimidação moral contra (alguém); ato violento, crueldade, força". No aspecto 
jurídico, o mesmo dicionário define o termo como o "constrangimento físico ou moral exercido sobre alguém, para obrigá-lo a submeter-se à vontade de outrem; coação" (Houaiss \& Villar, 2001, p. 2866).

Já a Organização Mundial da Saúde [OMS] (1993) define violência como sendo a imposição de níveis de dor e/ou sofrimento que poderiam ser evitados. Mas especialistas afirmam que o conceito é muito mais amplo e ambíguo do que essa mera constatação de que a violência é a imposição de dor e a agressão cometida por uma pessoa contra outra, até mesmo porque relatam que a dor é um conceito singular e muito difícil de ser definido, podendo ser esta física ou psíquica (Minayo, 2005).

De acordo com Minayo (2005), ocorre violência física quando é aplicado o uso da força para produzir feridas, injúrias e dor, com o objetivo claro ou não de ferir, deixando ou não marcas evidentes. São comuns tapas, agressões com diversos objetos e queimaduras causadas por objetos ou líquidos quentes. Embora a forma de violência mais evidente seja a física, existem diversas outras formas de violência, caracterizadas particularmente pela variação de intensidade, instantaneidade e perenidade (Sodré, 1992).

De acordo com Costa (2003), a violência é o emprego desejado da agressividade com finalidade destrutiva. É considerada como tal quando existe um ato agressivo que perpasse pelo desejo de aniquilação, onde o ator agressivo se mostra movido pelo sentimento de ódio.

Diante da imprevisibilidade das ações violentas, é crescente o sentimento de impotência perante elas por parte da população. Isso acaba gerando, no imaginário individual e coletivo também, a representação da violência como sendo uma força incontrolável. A partir disso, a postura mais comum adotada pelas pessoas acaba sendo a "lei do silêncio" e a submissão às exigências desse terror (Pino, 2007).

Apesar da quantidade de casos ocorridos frequentemente e de corrermos o risco da violência tornar-se "banal", quando um caso é divulgado pela mídia, ocorre uma revolta intensa, abalando a população. De acordo com Costa (2003), isso acontece devido ao fato de que tudo que o homem fez e que o torna humano nasceu contra a violência; assim, nos horrorizamos com ela não somente porque por ela o homem mostra-se destrutível, mas sim porque sabemos que a vida cultural existiu e permanece viva até hoje devido a pactos sem arma, por meio de atos de paz.
Kunzel (1998) propõe que vejamos a violência como pertencente ao registro do Real, uma violência destituída de sentido, para a qual não existam motivos racionais. A violência passa a ser vista como um último recurso do sujeito para que possa ser reconhecido. Arendt (1994) afirma que a violência aparece como último meio de tentar manter intacta uma estrutura de poder diante das contestações; assim, violência e poder são percebidos como opostos, pois um só existe na ausência de outro. Desse modo, só quem tem autoridade simbolicamente pode exercer a sua autoridade sem recurso à violência real.

\section{Lei, violência e psicanálise}

A forma de a sociedade evitar a violência na sua maioria é mediante leis; porém nem sempre estas são efetivas. Freud (1987b), em Totem e Tabu, mostra que foi por meio da violência que surgiram as primeiras leis, ao descrever a horda primitiva, onde o pai primevo monopolizava as mulheres e submetia os homens às suas ordens. Estes odiavam o pai $\mathrm{e}$ combinaram entre si de matá-lo e devorá-lo, unindo-se pela culpa do parricídio e incesto tornando-se autoimpostos. Entretanto, desistiram de lutar pela sucessão do pai primordial, pois estava sendo inútil e juntaram-se em um pacto social, acompanhado de renúncia às satisfações instintuais. Dessa forma, o pai morto veio tornar-se mais forte do que antes, gerando culpa, surgindo o apoio às leis, que são mantidas por intermédio da violência. A partir dessa culpa é que se estabeleceu/iniciou a condição humana. A lei então surge para reprimir e proibir os instintos, sabe-se que sempre que existe um tabu, há sempre por trás dele um desejo, e após o desejo, proibições que possam contê-lo.

Em O Mal-estar na Civilização, Freud falou sobre a agressividade como principal problema responsável pelo mal-estar na civilização, assim as pulsões destrutivas são responsáveis por atrapalhar os relacionamentos com os próximos, ameaçando a sociedade. Desse modo, relata que a civilização deveria estabelecer limites, leis para essas pulsões agressivas, mantendo suas manifestações sob controle. Acerca das leis, Freud (1987b, p. 150) afirma:

A lei apenas proíbe de fazer aquilo a que seus instintos os inclinam; o que a própria natureza proíbe e pune, seria supérfluo para a lei proibir e punir. Por

Psicol. Argum. 2013 abr./jun., 31 (73), 303-308 
conseguinte, podemos sempre com segurança pressupor que os crimes proibidos pela lei são crimes que muitos homens têm uma propensão natural a cometer (Freud, 1987b).

Calligaris (1993), referenciando os textos de Freud - Totem e Tabu e Mal-Estar na Civilização —, afirma que na civilização a autoridade é internalizada por cada um sob o modo de culpa ou dívida. Sendo internalizado, esse princípio da autoridade não precisa ser externo ao sujeito, uma presença real, constrangedora. Devido a essa internalização é que o convívio social é possível em nossa civilização. A internalização das leis requer que o sujeito recuse a origem social das mesmas. Assim, essa autoridade internalizada só faz sentido se o sujeito julga o que ele internalizou como sendo justo, desse modo ocorre uma passagem da razão objetiva da internalização para uma razão subjetiva. Dessa maneira, percebe-se que a autoridade só é mantida se aparece como fato e vontade de cada indivíduo, proporcionando que cada sujeito tenha uma espécie de tribunal individual para decidir o que é justo ou não (Calligaris, 1993).

Hoje, acreditamos que não exista mais uma lei eficiente na civilização que coloque limite e que possa conter esses instintos. Freud (1987a), em O Mal- estar na Civilização, afirma que vivemos hoje em uma sociedade com falsos valores e imediatista, na qual existe uma banalização do ato, do agir; ou seja, cada vez mais, os indivíduos agem e não simbolizam.

As leis são um dos pontos que a Psicanálise usa para se aproximar da construção da subjetividade. Para a mesma linha teórica, a lei está estritamente ligada ao Complexo de Édipo, pois, a partir dessa fase vivida no Édipo, estabelecem-se fatores como: os interditos básicos à ordem humana, onde também se delineiam as proibições, as relações intersubjetivas, e, juntamente, surge o universo das permissões. É nesse período também que devem ficar claras as interdições edípicas, como não matar o próximo, não ferir o corpo do outro, não tirar os bens e objetos dos outros para satisfazer seu desejo e/ou para ter prazer (Birman, 2001a).

Conforme Lacan (1998), é mediante a lei e o limite que a falta é inserida no sujeito mostrando que este não é completo, e sim faltante, sendo por meio desse sentimento de incompletude que existe a possibilidade de desejar. Assim, não existe desejo sem o limite e o ordenamento simbólico, passando-se a desejar nada mais que o objeto que o Outro deseja.

De acordo com Nogueira (2003), para a Psicanálise o ato infracional deve ser escutado como um apelo ao Outro. Interessa, assim, o local que o ato ocupa na subjetividade dessa pessoa, sendo essa prevalência de atuações um indicativo de como o indivíduo se coloca na vida, com uma prevalência do gozo sobre o desejo. A transgressão da Lei pode ser uma busca de limites, uma procura por um Pai castrador que possa interditar/barrar esses instintos.

De acordo com Freud, o mito do Édipo é que permite a entrada do indivíduo na cultura. A função do pai é de ser quem impede os impulsos da criança em relação à mãe e o que vai direcionar a criança para outros interesses na cultura. Dessa maneira, a família é o lugar ideal onde os complexos se organizam e equilibram-se, assim organizando o nível de desenvolvimento psíquico (Nogueira, 2003).

Birman (2001a), em A Economia do Gozo e os Impasses da Justiça, traz também a questão da onipotência, quando assinala que, para funcionar nas ordens da reciprocidade e da lei, o sujeito tem de perder e relativizar a sua onipotência. Caso contrário, o individuo irá acreditar que tem tudo o que é bom, e tudo que é ruim está no outro, pensando ter o poder de fazer tudo o que deseja na hora em que quiser.

Sendo assim, o sujeito fora da lei estaria permeado pelo narcisismo primário, apresentando características como: acreditar que possa impor seus ideais e instituir a lei, não se submetendo a nada que lhe seja exterior; ele não vê a singularidade e a diferença de cada um, nem a interioridade dos outros; autoriza-se a retirar coisas dos outros quando bem entende; usa muitas vezes da violência para satisfazer seus desejos; age de forma predatória; vê o outro como um simples pedaço de carne que possui bens e objetos que atiçam sua cobiça, nada além disso; vê o indivíduo na sua frente como um depositário daquilo de que não gosta, que lhe causa dor, desprazer e desconforto (Birman, 2001b). Segundo Birman (2001b), um sujeito fora de si pode remeter-se para algo da ordem da negatividade, do ponto de vista de um discurso sobre valores; mas se na condição fora de si o indivíduo tiver que ser internado, este se encontra em um estado mental não condizente com as exigências mínimas da sociabilidade.

Percebe-se, assim, por meio dos atos de violência que vêm aumentando na sociedade moderna, um fracasso da lei, da função paterna. Nesse sentido, essa 
autoridade simbólica a que se refere Calligaris está enfraquecida. A função paterna não se mede pelo gozo que ela permite ter, mas pelo que ela interdita. Essa função paterna é que põe um limite no sujeito e em contrapartida lhe dá cidadania, um lugar simbólico e alguns ideais de referência (Calligaris, 1991). Conforme o autor, é em busca desse nome que não lhe foi dado que o ato violento passa a ser simbólico, no qual o sujeito espera encontrar a lei, mesmo que seja sob o modo de sanção. Assim, o sujeito espera que seus atos tragam para ele algum lugar simbólico já que seus laços sociais não o deram.

De acordo com Cavalcante (2002), a violência surge como uma tentativa de inclusão/manutenção do laço social e não como um desmoronamento do laço na atualidade. 0 emprego da força e da agressividade atualmente vem relacionado a uma maneira desordenada do indivíduo na resolução de seus conflitos e em busca da satisfação de necessidades individuais e sociais, visando incluir-se no laço social. A violência aparece como meio de entrada ou manutenção do laço social, representa a pulsão destrutiva misturada com a pulsão de morte, assim não se pode dizer que há uma prevalência da pulsão de morte sobre a pulsão de vida, já que o que está em jogo não é a destruição e sim a sociabilidade humana.

Atualmente, a cultura vem sendo caracterizada pela ausência de limites; assim, entende-se o espaço que a violência vem ocupando no cotidiano. Anteriormente, acontecia a introjeção da lei de interdição ocasionando a instauração do sentimento de culpa, proporcionando a repressão das pulsões agressivas. Desse modo, para que a violência generalizada pudesse ser impedida, a civilização deveria reforçar esse sentimento de culpa (Enriquez, 1990).

\section{Considerações finais}

O crescente aumento da violência é visível no nosso dia a dia; ela não está presente somente nas capitais, mas também se espalha pelo interior, o que se torna cada vez mais preocupante. Uma das causas do crescimento da violência urbana no Brasil é a aceitação social da constante ruptura das normas jurídicas e o desrespeito das pessoas à noção de cidadania.

Consequentemente, observa-se que a violência tem sido percebida como uma desestabilização do equilíbrio social da civilização, sendo permeada pela falta de leis, autoridades que sirvam como referência do que se pode ou não fazer, não existindo dentro de muitos a autoridade simbólica. Nota-se que vivemos, atualmente, em um momento de confusão dos valores sociais, estando as famílias cada vez mais desagregadas e os pais muitas vezes ausentes em suas funções.

Devido a essa falta, juntamente com as questões sociais existentes, muitos acabam indo em busca dessa autoridade simbólica, essa castração que lhe nomeia na sociedade, o inclui no laço social. Essa busca se dá muitas vezes por meio de atos agressivos, de violência na procura de uma autoridade, nem que seja pelo viés da sanção, ou seja, a transgressão da lei como uma maneira de buscar limites.

De acordo com a revisão bibliográfica realizada, entende-se que a violência não é um fenômeno novo e que não devemos compreendê-la como um fator de caráter individual (inato ao homem) e sim, contrariamente, trata-se de um fenômeno social, diferenciado do ponto de vista cultural e histórico.

\section{Referências}

Andrade, E. V. Bezerra, B. Jr. (2009). Uma reflexão acerca da prevenção da violência a partir de um estudo sobre a agressividade humana. Revista Ciência e Saúde Coletiva, 14(2), 444-453.

Arendt, H. (1994). Sobre a violência. Rio de Janeiro: Relume Dumará.

Birman, J. (2001a). A economia do gozo e os impasses da justiça. Uma leitura psicanalítica da justiça. In J. Birman. (2001). Mal-estar na atualidade: A psicanálise e as novas formas de subjetivação. Rio de Janeiro: Civilização Brasileira.

Birman, J. (2001b). 0 sujeito de colarinho branco. 0 dentro-de-si e o fora-de-si nas figurações atuais da subjetividade. In J. Birman. (2001). Mal-estar na atualidade: A psicanálise e as novas formas de subjetivação. Rio de Janeiro: Civilização Brasileira.

Calligaris, C. (1991). Sedução totalitária. In L. T. Aragão, O. Souza, J. F. Costa, \& C. Calligaris. (1991). Clínica do social: Ensaios. São Paulo: Escuta.

Calligaris, C. (1993). Psicanálise e sistema social. Porto Alegre: Unisinos.

Cavalcante, L. T. (2002). Função paterna, fratria e violência: sobre a constituição do socius na psicanálise freudiana. PsicoUSF, 7(2), 195-200. 
Costa, J. F. (2003). À guisa de introdução: Por que a violência? Por que a paz? In J. F. Costa. (2003). Violência e psicanálise. (3. ed.). Rio de Janeiro: Edições Graal.

Enriquez, E. (1990). Da Horda ao Estado: Psicanálise do vínculo social. Rio de Janeiro, Jorge Zahar Editor.

Freud, S. (1987a). O Mal-estar na civilização [1930] In S. Freud. Obras psicológicas completas. Rio de Janeiro: Ed. Imago.

Freud, S. (1987b). Totem e Tabu. In S. Freud. Obras psicológicas completas. Rio de Janeiro: Ed. Imago.

Houaiss, A., \& Villar, M. S. (2001). Dicionário Houaiss da língua portuguesa. Rio de Janeiro: Objetiva.

Kunzel, J. (1998). Violência social. In M. Fleig. Psicologia e sintoma social II. (pp. 49-58). Porto Alegre: Unisinos.

Lacan, J. (1998). 0 estádio do espelho como formador da função do eu tal como nos é revelada na experiência psicanalítica. In J. Lacan, \& V. Riveiro. (Trad.). (1998). Escritos. Rio de Janeiro: Jorge Zahar.

Martins, J., Catozzi, C., Sayegh, F., \& Barian, I. C. D. (2005). 0 professor e o aluno em liberdade assistida: um estudo exploratório. Psicologia Escolar e Educacional, $9(1), 37-46$
Martins, J., \& Bicudo, M. A.V. (1989). A Pesquisa qualitativa em psicologia: Fundamentos e recursos básicos. São Paulo: Moraes.

Minayo, M. C. S. (2005). Violência: um velho-novo desafio para a atenção à saúde. Revista Brasileira de Educação Médica, 29(1), 55-63.

Nogueira, C. S. P. (2003). O adolescente infrator. In F. O. Barros (Coord.). Tô fora: o adolescente fora da lei - o retorno da segregação. (pp. 13-24). Belo Horizonte: Del Rey,

Organização Mundial de Saúde [OMS]. (1993). Salud Mundial. Genebra: OMS.

Pino, A. (2007). Violência, educação e sociedade: um olhar sobre o Brasil contemporâneo. Revista Educação e Sociedade, 8(100).

Sodré, M. (1992). O social irradiado: Violência urbana, neogrotesco e mídia. Rio de Janeiro: Cortez. 